\title{
Stress and Coping Strategies Among Nursing Students
}

\author{
Emad Shdaifat ${ }^{1}$, Aysar Jamama ${ }^{1}$ \& Mohammed AlAmer ${ }^{1}$ \\ ${ }^{1}$ Nursing College, Imam Abdulrahman Bin Faisal University, Saudi Arabia \\ Correspondence: Dr Emad Shdaifat, College of Nursing, Imam Abdulrahman Bin Faisal University, 31451 \\ Dammam, Saudi Arabia. Tel: 966-13-333-1642. E-mail: ealshdaifat@iau.edu.sa
}

Received: February 7, 2018 Accepted: March 18, 2018 Online Published: March 20, 2018

doi:10.5539/gjhs.v10n5p33 URL: https://doi.org/10.5539/gjhs.v10n5p33

\begin{abstract}
Introduction: Nursing students suffer from high levels of stress related to academic assignments in addition to clinical skills training. As a psychosocial phenomenon, stress affects students' academic achievement and wellbeing. Coping mechanisms help students deal with the challenges arising from stress.

Aims: To illustrate the level of stress and common stressors among nursing students; to describe the difference in stress level related to demographic data; and to identify coping mechanisms used by nursing students.

Methods: A descriptive cross-sectional study was carried out to determine the type of stress and coping strategies among nursing students. The level of stress was evaluated through Perceived Stress Scale (PSS) and type of coping strategies were assessed by use of Coping Behaviours Inventory (CBI).
\end{abstract}

Results: Students perceived moderate level of stress, most commonly attributed to assignments and workload, teachers and nursing staff, peers and daily life, and taking care of patients. The most frequently used coping mechanism was problem solving. The study found that age, GPA, education level and residence are good predictors of the use of transference as a coping behaviour.

Conclusion: A moderate level of stress among students illustrates the need for stress management programs and the provision of suitable support.

Keywords: stress, coping, student, nursing

\section{Introduction}

Student at the university level experience high level of stress, related to worry about successes, availability of time, engagement in patient care (Mohamed \& Ahmed, 2012). There are many sources of stress among university student, which can be related to academic workload, many assignments, and expose to a new setting. The rate and level of stress and depression is an alarm among students in different academic fields (El Ansari, Adetunji, \& Oskrochi, 2014).

Nursing students practice a long hour of study and inadequate time for other activities (Gibbons, Dempster, \& Moutray, 2011). In addition, they spend a substantial time in the clinical areas, with the heavy responsibility of being accountable for patients (Reeve, Shumaker, Yearwood, Crowell, \& Riley, 2013). Moreover, financial burden, struggling to manage time and using high-tech machines are all additional stressors in many cases (Seyedfatemi, Tafreshi, \& Hagani, 2007).

Clinical practice in nursing is essential to train students to be professional nurses through applying academic skills in practice, helping bridge the theory-practice gap that commonly faces newly qualified nurses (Labrague, 2014). Students generally undertake basic courses for clinical practice from the beginning of the educational program, thus they face this great escalation in addition to the general burdens of managing their academic activities, which is inherently stressful (Reeve et al., 2013).

The stress can be related to the short time to study and spend many hours in clinical setting such as hospitals and health centres (Shriver \& Scott-Stiles, 2000). Some student can't cope with their stressors because they don't have the suitable study plan. In general, student cannot eradicate the stress but they can reduce it, so coping is an element that help in preserve their psychosocial (Singh, Sharma, \& Shama, 2011).

Many studies found that nursing student have high level of stress comparing with other students (Gibbons et al., 2011; Goff, 2011; Reeve et al., 2013). Coping strategies to manage stress through social care can positively reduce 
levels of stress and promote health (Lo, 2002; Payne, 2001).

In Saudi, the students joint the nursing school in between the ages of 18-20 years (upon completion of high school), and are then faced with some patient care responsibilities for which they lack the prerequisite professional knowledge and skills, which is the root of the stress they face (Sheila Sheu, Lin, \& Hwang, 2002).

Despite the universal acknowledgement of the intense stress faced by students, very little is known in terms of epidemiological figures around stress level and factors. Largely due to cultural attitudes that affirm the inevitability and normality of major stress among students, including among nursing researchers who themselves have gone through such stressful processes, very few studies have explored the prevalence of stress among students. This study constitutes an effort to illustrate levels of stress and to identify common stressors among nursing students, describe the differences in stress levels and coping behaviour related to demographic variables (age, gender, marital status, education level, smoking habit, Body Mass Index (BMI), residence, family income, sleeping hours and Grade Point Average (GPA)), find out the relation between type of stress and coping strategies and to find out the coping mechanism used by nursing students.

\section{Methods}

\subsection{Setting}

A cross-sectional study was conducted at University of Dammam in Saudi Arabia for 6 months (Nov to April 2017) at college of nursing. The college deliver a bachelor degree in nursing and offering the bridging program as well.

\subsection{Sampling and Sampling Criteria}

The population sample will comprised of all student in nursing college at different levels during the study period. Convenient sampling was used to collect data from students who were studying nursing during the study period.

\subsection{Survey Instruments}

First, The Perceived Stress Scale (PSS) Questionnaire was used to collect data for the purpose of the study (S Sheu et al., 1997). The questionnaire required students to record their impression about stress level. It included students from first to fourth year. English version and Arabic translation was used in this study, and back-translation was used to translate the English version of the questionnaire into Arabic language.

This tool was established by S Sheu et al. (1997). It was used to explore types and level of stress that occurred in clinical settings. A 5-point Likert type scale was used which consisted of 29 items, and clustered into six factors. These six factors were categorised as stress from; taking care of patients, teachers and nursing personnel, tasks and workload, peers and daily life, stress from poor level of specialized knowledge and skills, and from the clinical setting. Scores were ranged from 0 to 116. A higher score indicated a higher degree of stress. The following scaling was used to determine the level of stress; high stress (2.67-4.0), moderate stress (1.34-2.66) and low stress (0-1.33) (Labrague, 2014). In this study, internal consistency reliability for PSS as measured by Cronbach's alpha for the total scale was 0.94 , and for the subscales mentioned above: $0.88,0.80,0.78,0.78,0.69$ and 0.70 , respectively. A Cronbach's alpha of 0.89 indicates high internal consistency (Chan, So, \& Fong, 2009; Sheila Sheu et al., 2002; S Sheu et al., 1997).

Second, Coping behaviour inventory (CBI) established by (Sheila Sheu et al., 2002) was used to find out nursing students' coping strategies. It consists of 19 items classified into four types; avoidance behaviours, problem solving behaviour, optimistic coping behaviour and transference behaviour.

Each item was rated into on a 5 Likert scale, high scores indicate more used of coping behaviour. Cronbach's alpha coefficient was 0.76 (Sheila Sheu et al., 2002). In this study, internal consistency reliability for CBI as measured by Cronbach's alpha for the total scale was 0.70 , and for the subscales mentioned above were $0.62,0.87,0.56$, and 0.41 , respectively.

\subsection{Ethical Considerations}

Ethical approval was obtained from the Institutional Review Board (IRB) of University of Dammam. Students were given the information sheet to read and the research's purpose, significance, benefits were explained verbally. Students were assured that their participation will be completely voluntary.

\subsection{Data Collection}

Data were collected during the teaching hours in the university. All the students were invited to participate in the surveys. 


\subsection{Data Analysis}

The analysis of data was carried out using SPSS version 20. Descriptive statistics and frequency distributions were performed to describe the baseline characteristics of study samples and to determine the level of stress. Continuous data on the stress were then assessed for normality. Descriptive crosstabs analyses were conducted to determine the stress level among different level of students. A p-value of less than 0.05 was considered statistically significant.

\section{Results}

\subsection{Participants' Characteristics}

A total of 184 students were approached and invited to participate in the study, most of them were male (67.4\%), single $(65.8 \%)$, in the bachelor degree $(72.8 \%)$, non-smokers $(82.6 \%)$ and living with their families $(80.4 \%)$. The mean age of the participants was 23.9 years $(\mathrm{SD}=5.07)$, their $\mathrm{BMI}$ was $25.3(\mathrm{SD}=5.40)$, and their GPA was 3.80 $(\mathrm{SD}=0.53)$. The family income (parent income) for the students was $11668 \mathrm{SR}(\mathrm{SD}=7733)$, and their sleeping hours' mean was 7 hours $(\mathrm{SD}=1.81)$ (Table 1).

Table 1. Participants' Demographics $(\mathrm{n}=184)$

\begin{tabular}{llll}
\hline \multirow{2}{*}{ Gender } & & No. & \% \\
& male & 124 & 67.4 \\
Marital Status & Female & 60 & 32.6 \\
\hline \multirow{2}{*}{ Education Level } & Single & 121 & 65.8 \\
& Married & 63 & 34.2 \\
\hline \multirow{2}{*}{ Smoking * } & Bachelor & 134 & 72.8 \\
& Bridging & 50 & 27.2 \\
\hline \multirow{2}{*}{ Residence } & Yes & 30 & 16.3 \\
& No & 152 & 82.6 \\
\hline Age & with Family & 148 & 80.4 \\
BMI & Alone & 36 & 19.6 \\
GPA & & Median & IQR \\
Family income & $23.9(5.07)$ & 23.0 & 9.0 \\
Sleeping hour & $25.3(5.40)$ & 24.0 & 7.39 \\
\hline
\end{tabular}

* Missing Value.

\subsection{Level of Stressors Perceived by Students}

The level of stress and types of stressors perceived by nursing students were tabulated in Table 2 . The degree of stress perceived by the participants was $1.57(\mathrm{SD}=0.72)$. The most common type of stressor perceived by students was stress from assignment and workload $(\mathrm{M}=1.82, \mathrm{SD}=0.90)$, students felt stressed when they were worry about bad grades, experience pressure of clinical practice, and not meet teachers' expectations. The second highest causes of stress were caused by teacher and nursing staff $(\mathrm{M}=1.80, \mathrm{SD}=0.83)$ such as experience discrepancy between theory and practice, do not know how to discuss patients' illness with teachers, etc.

The third most common stressors encountered by students were stress from taking care of patients $(\mathrm{M}=1.47$, $\mathrm{SD}=0.86$ ) as; Lack of experience and ability in providing nursing care, do not know how to help patients with physio-psycho-social problems etc. The least sources of stress were caused by the environment $(\mathrm{M}=1.28, \mathrm{SD}=0.90)$ such as; feel stressed in the hospital environment where clinical practice takes place, unfamiliar with the ward facilities, and feel stressed from the rapid change in patient's condition. 
Table 2. Stressors Perceived by Nursing Students $(\mathrm{n}=184)$

\begin{tabular}{|c|c|c|c|}
\hline STRESS Factor/Items & $\begin{array}{c}\text { Factor } \\
\text { Ranking }\end{array}$ & Mean & SD \\
\hline Overall PSS & & 1.57 & 0.72 \\
\hline 1. Stress from taking care of patients & 3 & 1.47 & 0.86 \\
\hline Lack of experience and ability in providing nursing care and in making judgments & & 1.51 & 1.06 \\
\hline Do not know how to help patients with physio-psycho-social problems & & 1.47 & 1.07 \\
\hline Unable to reach one's expectations & & 1.29 & 1.10 \\
\hline Unable to provide appropriate responses to doctors', teachers', and patients' questions & & 1.76 & 1.10 \\
\hline Worry about not being trusted or accepted by patients or patients' family & & 1.51 & 1.28 \\
\hline Unable to provide patients with good nursing care & & 1.48 & 1.31 \\
\hline Do not know how to communicate with patients & & 1.27 & 1.18 \\
\hline Experience difficulties in changing from the role of a student to that of a nurse & & 1.49 & 1.15 \\
\hline 2. Stress from teachers and nursing staff & 2 & 1.80 & 0.83 \\
\hline Experience discrepancy between theory and practice & & 1.77 & 1.10 \\
\hline $\begin{array}{l}\text { Do not know how to discuss patients' illness with teachers, and medical and nursing } \\
\text { personnel }\end{array}$ & & 1.53 & 1.13 \\
\hline Feel stressed that teacher's instruction is different from one's expectations & & 1.85 & 1.06 \\
\hline Medical personnel lack empathy and are not willing to help & & 1.74 & 1.28 \\
\hline Feel that teachers do not give fair evaluation on students & & 2.21 & 1.40 \\
\hline Lack of care and guidance from teachers & & 1.73 & 1.25 \\
\hline 3. Stress from assignments and workload & 1 & 1.82 & 0.90 \\
\hline Worry about bad grades & & 2.73 & 1.25 \\
\hline Experience pressure from the nature and quality of clinical practice & & 1.70 & 1.16 \\
\hline Feel that one's performance does not meet teachers' expectations & & 1.90 & 1.22 \\
\hline $\begin{array}{l}\text { Feel that the requirements of clinical practice exceed one's physical and emotional } \\
\text { endurance }\end{array}$ & & 1.20 & 1.21 \\
\hline Feel that dull and inflexible clinical practice affects one's family and social life & & 1.55 & 1.34 \\
\hline 4. Stress from peers and daily life & 4 & 1.42 & $\mathbf{0 . 8 8}$ \\
\hline Experience competition from peers in school and clinical practice & & 1.20 & 1.20 \\
\hline Feel pressure from teachers who evaluate students' performance by comparison & & 2.05 & 1.38 \\
\hline Feel that clinical practice affects one's involvement in extracurricular activities & & 1.46 & 1.21 \\
\hline Cannot get along with other peers in the group & & 0.93 & 1.05 \\
\hline 5. Stress from lack of professional knowledge and skills & 5 & 1.30 & 1.03 \\
\hline Unfamiliar with medical history and terms & & 1.26 & 1.08 \\
\hline Unfamiliar with professional nursing skills & & 1.19 & 1.19 \\
\hline Unfamiliar with patients' diagnoses and treatments & & 1.45 & 1.17 \\
\hline 6. Stress from the environment & 6 & 1.28 & 0.90 \\
\hline Feel stressed in the hospital environment where clinical practice takes place & & 1.28 & 1.15 \\
\hline Unfamiliar with the ward facilities & & 1.11 & 1.12 \\
\hline Feel stressed from the rapid change in patient's condition & & 1.43 & 1.13 \\
\hline
\end{tabular}




\subsection{Coping Strategies Frequently Used for Relieving Stress}

Coping strategies commonly used by nursing students are presented in Table 3, the most frequent coping strategy was problem solving $(\mathrm{M}=2.53, \mathrm{SD}=0.87)$ for example, setting up objectives, adopting strategies to solve problems, making plans and listing priorities, finding the meaning of stressful incidents, and employing experience. The second coping strategies used by students was staying optimistic $(\mathrm{M}=2.28, \mathrm{SD}=0.73)$, and the least coping strategies used by students was avoidance $(\mathrm{M}=1.17, \mathrm{SD}=0.61)$.

Table 3. Copying mechanism by Nursing Students $(\mathrm{n}=184)$

\begin{tabular}{|c|c|c|c|}
\hline & Factor Ranking & Mean & SD \\
\hline 1. Avoidance & 4 & 1.17 & 0.61 \\
\hline 1. To avoid difficulties during clinical practice & & 1.92 & 1.12 \\
\hline 2. To avoid teachers & & 1.42 & 1.20 \\
\hline 3. To quarrel with others and lose temper & & 0.48 & 0.78 \\
\hline 4. To expect miracles so one does not have to face difficulties & & 0.98 & 1.11 \\
\hline 5. To expect others to solve the problem & & 1.19 & 0.91 \\
\hline 6. To attribute to fate & & 1.06 & 1.09 \\
\hline 2. Problem solving & 1 & 2.53 & 0.87 \\
\hline 7. To adopt different strategies to solve problems & & 2.51 & 1.15 \\
\hline 8. To set up objectives to solve problems & & 2.51 & 1.16 \\
\hline 9. To make plans, list priorities, and solve stressful events & & 2.43 & 1.17 \\
\hline 10. To find the meaning of stressful incidents & & 2.29 & 1.12 \\
\hline 11. To employ past experience to solve problems & & 2.86 & 1.09 \\
\hline 12. To have confidence in performing as well as senior schoolmates & & 2.55 & 1.15 \\
\hline 3. Stay optimistic & 2 & 2.28 & 0.73 \\
\hline 13. To keep an optimistic and positive attitude in dealing with everything in life & & 2.96 & 1.17 \\
\hline 14. To see things objectively & & 2.53 & 1.08 \\
\hline 15. To have confidence in overcoming difficulties & & 2.78 & 1.13 \\
\hline 16. To cry, to feel moody, sad, and helpless & & 0.84 & 1.11 \\
\hline 4. Transference & 3 & 1.90 & 0.81 \\
\hline 17. To feast and take a long sleep & & 1.23 & 1.18 \\
\hline 18. To save time for sleep and maintain good health to face stress & & 2.18 & 1.18 \\
\hline 19. To relax via TV, movies, a shower, or physical exercises (ballplaying, jogging) & & 2.29 & 1.23 \\
\hline
\end{tabular}

\subsection{Correlation Between Stress Level and Coping Behaviour}

A Pearson correlation was carried out to determine the relationship between PSS subscales and CBI subscales. There was a positive moderate correlation between "Avoidance" and all the PSS subscales, with "Stress from taking care of patients" $(\mathrm{r}=0.33, \mathrm{p}=0.001)$, "Stress from teachers and nursing staff" $(\mathrm{r}=0.26, \mathrm{p}=0.001)$, "Stress from assignments and workload" ( $(\mathrm{r}=0.40, \mathrm{p}=0.001)$, "Stress from peers and daily life" $(\mathrm{r}=0.29, \mathrm{p}=0.001)$, "Stress from lack of professional knowledge and skills" ( $\mathrm{r}=0.30, \mathrm{p}=0.001)$, and "Stress from the environment" $(\mathrm{r}=$ $0.35, \mathrm{p}=0.001$ ) (Table 4). In addition, "Problem solving" was correlated with "Stress from taking care of patients" $(\mathrm{r}=-0.16, \mathrm{p}=0.04)$, and with "Stress from peers and daily life" $(\mathrm{r}=-0.17, \mathrm{p}=0.03)$. 
Table 4. The Pearson Correlation among type of Stressors and Coping behaviours

\begin{tabular}{lllll}
\hline & Avoidance & Problem solving & Stay optimistic & Transference \\
\hline Stress from taking care of patients & $\boldsymbol{r}=\mathbf{0 . 3 3} * *$ & $\boldsymbol{r}=\mathbf{- 0 . 1 6 4 *}$ & $r=-0.07$ & $r=0.07$ \\
Stress from teachers and nursing staff & $\boldsymbol{r}=\mathbf{0 . 2 6} * *$ & $r=-0.14$ & $r=0.03$ & $r=0.02$ \\
Stress from assignments and workload & $\boldsymbol{r}=\mathbf{0 . 4} * *$ & $r=0.10$ & $r=-0.1$ & $r=0.03$ \\
Stress from peers and daily life & $\boldsymbol{r}=\mathbf{0 . 2 9 * *}$ & $r=-0.06$ & $r=-0.04$ & $r=-0.04$ \\
Stress from lack of professional knowledge and skills & $\boldsymbol{r}=\mathbf{0 . 3 0 * *}$ & $\boldsymbol{r}=\mathbf{- 0 . 1 7 *}$ & $r=-0.11$ & $r=0.01$ \\
Stress from the environment & $\boldsymbol{r}=\mathbf{0 . 3 5 * *}$ & $r=-0.05$ & $r=-0.08$ & $r=0.03$ \\
\hline
\end{tabular}

** Correlation is significant at the 0.01 level (2-tailed).

* Correlation is significant at the 0.05 level (2-tailed).

\subsection{Differences Between Stress Level, Coping Behaviour and Demographic Variables}

This study found that gender and smoking were statistically significantly with stress level $\mathrm{t}(182)=-2.37, \mathrm{p}=0.019$ and $\mathrm{t}(180)=-1.89, \mathrm{p}=0.027$, respectively. On the other hand, gender was statistically significantly with coping behaviour using "Problem solving" level $\mathrm{t}(169)=2.44, \mathrm{p}=0.016$ and type residence had statistically significantly with coping behaviour using "Transference" level $\mathrm{t}(180)=-3.11, \mathrm{p}=0.002$.

\subsection{Correlation Between Stress Level and Demographic Variables}

Correlation was found a negative week correlation between stress level and income $(r=-0.22, p=0.024)$. Moreover, Spearman correlation found a week positive correlation between coping behaviour of "Transference" and sleeping hour $\left(\mathrm{r}^{\mathrm{s}}=0.18, \mathrm{p}=0.017\right)$.

\subsection{Regression Analysis for Stress Level, Coping Behaviour and Demographic Variables}

No significant result was detected between stress level and Demographic variables. Furthermore, multiple linear regression was carried out to predict the CBI subscales and other variables (demographic variables) and the only significant difference was detected with Transference. The multiple regression model with all four predictors (age, GPA, education level and residence) produced $\mathrm{R}^{2}=0.30, \mathrm{~F}(10.82)=3.51, \mathrm{P}<0.001$.

\section{Discussion}

This study explains the level of stress and coping behavior among nursing students. The stress level among students was moderate. Moreover, the moderate level of stress was caused by; assignments and workload, teachers and nursing staff, peer and daily life, and finally stress from taking care of patients. A low level of stress was caused by lack of professional knowledge and skill and stress from the environment. The students used problem solving to cope with stress as the highest used mechanism and the lowest used mechanism was avoidance.

There was a moderate positive correlation between Avoidance as a coping behavior and all the PSS subscales, so as the level of stress becomes higher the students will use more coping behavior. In the contrast, there was a negative weak correlation between problem solving as a coping behavior and stress from taking care of patients and lack of professional; knowledge and skills.

As the income increased the level of stress reduced. Furthermore, the study found that as the sleeping hour increased the students will use transference as a coping behavior. Age, GPA, education level and residence were a good predictor for transference as a coping behavior.

\subsection{Type of Stressors}

The stress level among students was moderate. Hong Kong nursing students have a moderate level of stress (Bayram \& Bilgel, 2008; Chan et al., 2009; Labrague, 2014; Mohamed \& Ahmed, 2012; Shaban, Khater, \& Akhu-Zaheya, 2012; Sheila Sheu et al., 2002) and according to Mohamed and Ahmed (2012) the majority of students complain of high level of stress. Moreover, Ross et al. (2005) stated that the level of stress was high.

In this study, students reported that the most common sources of stress were assignments and workload, teachers and nursing staff, and finally stress from taking care of patients were the most common sources of stress, this is in line with Jimenez, Navia-Osorio, and Diaz (2010), who found that stress from assignment and workload was one of the major stresses experienced by more than 300 nursing students in their study in Spain. Equally, in some other countries like China (Zhao, Lei, He, Gu, \& Li, 2015), Hong Kong (Chan et al., 2009) (Chen \& Hung, 2014; Jones 
\& Johnston, 2006). On the national and regional level, many researchers found that, stress of assignments and workloads were the main causes of stress among Saudi and Jordanian nursing students (Al-Zayyat \& Al-Gamal, 2014; Mohamed \& Ahmed, 2012). However, some studies found that stress from assignments and workload was low among nursing students (Sheila Sheu et al., 2002). The possible reason for this may be the overcrowded students' time table and heavy curriculum with many assignments and other coursework activities.

This study found that stress from teachers and nursing staff were significant and one of the most common sources of stress they perceived, in like manner with many studies; Chen and Hung (2014); Evans and Kelly (2004); Nolan and Ryan (2008). May be the reason behind that was the time of communication between teachers, nursing staff and students was not enough (Timmins \& Kaliszer, 2002). Moreover, some clinical environments were not welcoming the new students (Kaur et al., 2009).

According to this study, taking care of patients was one of the main common stress sources, many researchers stated that taking care of patients was the prominent stress perceived by students (Chang et al., 2007). In addition, Zupiria et al. (2007) found that lack of knowledge and skills was the most common stresses. Alterations in ordering the stresses can be affected by culturally, educationally and environmental variables.

\subsection{Coping Mechanisms}

This study found that problem solving strategies were the most commonly deployed mechanisms of coping with stress, while avoidance was the least, similar to previous studies (Al-Zayyat \& Al-Gamal, 2014; Chan et al., 2009; Chen \& Hung, 2014). Conversely, Shaban et al. (2012) found that avoidance was the most commonly used mechanism among students in dealing with different stresses. Avoidance is generally recognized as only a temporary measure and not a sustainable solution to address underlying stressors.

\subsection{Stress and Coping Skills Correlations}

While our study found that there is a positive correlation between avoidance and overall perceived stress sources, some studies agreed with our results while other studies mentioned that this positive correlation were found between avoidance and one or two of the PSS subscales (Chan et al., 2009; Shaban et al., 2012).

The present study showed that there is a negative correlation between using problem solving technique as a coping skill and the stress of taking care of patients. In parallel with Chan et al. (2009), who found that each unit increased in stress from taking care of patient will decrease one fifth point of using problem solving. In addition, they found that there is a significant positive relationship between sleep and using transference as a coping skill (Chan et al., 2009).

Age, GPA, education level and residence were good predictors for transference as a coping behaviour. Chan et al. (2009), found that the main predictor of avoidance as coping mechanism was years of study and religion, which explain $6.5 \%$ of the variance. According to Home (1997), students with low income have more stress. On the other hand, Maville, Tucker, and Kranz (2004), found that income is inversely proportional to stress levels.

\subsection{Limitation}

The main limitation of this study was its cross-sectional design, which does not explore causal relationships between variables. Furthermore, the implications of the findings are limited due to including only a single institution, and the general recruitment of students prevented exploring the particular needs of certain years during the nursing program, which narrows the scope of the emergent picture of stress among nursing students and its magnitude. In addition, there could be respondent bias in fill the questionnaires.

\section{Conclusion}

Nursing students experience a moderate level of stress because of assignment and workload, teacher and nursing staff, peers and daily life, and taking care of patients. The most commonly used coping mechanism to relieve stress is problem solving. Nursing faculties can help meet student needs by acknowledging their complaints of heavy workloads and extra assignments, offering supportive services. Faculties should pay attention to the stress level of students, and focus on offering a stress management program for that (Ross, 2005, Thailand). Managers should focus on the stress level during orientation programs.

\section{Recommendation}

A stress management program should be applied as an immediate measure to address stress, and its effectiveness should be checked longitudinally, with consideration of families and peers as well as nursing students themselves. Further research should explore the particular factors exacerbating the experience of stress among students relative to curriculum design. Nursing educators and curriculum designers should consider the optimization of curriculums 
to offer a less stressful experience for students (e.g. ensuring low-intensity academic requirements when students undertake clinical placements).

\section{Acknowledgements}

We would like to thank Aisha Sardar and Sara AL Zahid for the help during the data collection stage. We would like to thanks all the students who participated in the study for their valuable time given for filling the questionnaires.

\section{Competing Interests Statement}

The authors declare that there are no competing or potential conflicts of interest.

\section{References}

Al-Zayyat, A. S., \& Al-Gamal, E. (2014). Perceived stress and coping strategies among Jordanian nursing students during clinical practice in psychiatric/mental health courses. International Journal of Mental Health Nursing, 23(4), 326-335. https://doi.org/10.1111/inm.12054

Bayram, N., \& Bilgel, N. (2008). The prevalence and socio-demographic correlations of depression, anxiety and stress among a group of university students. [Article]. Social Psychiatry \& Psychiatric Epidemiology, 43(8), 667-672. https://doi.org/10.1007/s00127-008-0345-x

Chan, C. K. L., So, W. K. W., \& Fong, D. Y. T. (2009). Hong Kong Baccalaureate Nursing Students' Stress and Their Coping Strategies in Clinical Practice. Journal of Professional Nursing, 25(5), 307-313. https://doi.org/10.1016/j.profnurs.2009.01.018

Chang, E. M. L., Bidewell, J. W., Huntington, A. D., Daly, J., Johnson, A., Wilson, H., . . Lambert, C. E. (2007). A survey of role stress, coping and health in Australian and New Zealand hospital nurses. International Journal of Nursing Studies, 44(8), 1354-1362. https://doi.org/10.1016/j.ijnurstu.2006.06.003

Chen, Y.-W., \& Hung, C.-H. (2014). Predictors of Taiwanese baccalaureate nursing students' physio\&\#x2013;psycho-social responses during clinical practicum. Nurse Education Today, 34(1), 73-77. https://doi.org/10.1016/j.nedt.2013.02.021

El Ansari, W., Adetunji, H., \& Oskrochi, R. (2014). Food and mental health: relationship between food and perceived stress and depressive symptoms among university students in the United Kingdom. Cent Eur $J$ Public Health, 22(2), 90-97. https://doi.org/10.21101/cejph.a3941

Evans, W., \& Kelly, B. (2004). Pre-registration diploma student nurse stress and coping measures. Nurse Education Today, 24(6), 473-482. https://doi.org/10.1016/j.nedt.2004.05.004

Gibbons, C., Dempster, M., \& Moutray, M. (2011). Stress, coping and satisfaction in nursing students. Journal of Advanced Nursing, 67(3), 621-632. https://doi.org/10.1111/j.1365-2648.2010.05495.x

Goff, A. M. (2011). Stressors, academic performance, and learned resourcefulness in baccalaureate nursing students. Int J Nurs Educ Scholarsh, 8, Article 1. https://doi.org/10.2202/1548-923X.2114

Home, A. M. (1997). Learning the Hard Way. Journal of Social Work Education, 33(2), 335-346. https://doi.org/10.1080/10437797.1997.10778874

Jimenez, C., Navia-Osorio, P. M., \& Diaz, C. V. (2010). Stress and health in novice and experienced nursing students. Journal of Advanced Nursing, 66(2), 442-455. https://doi.org/10.1111/j.1365-2648.2009.05183.x

Jones, M. C., \& Johnston, D. W. (2006). Is the introduction of a student-centred, problem-based curriculum associated with improvements in student nurse well-being and performance? An observational study of effect. International Journal of Nursing Studies, 43(8), 941-952. https://doi.org/10.1016/j.ijnurstu.2005.10.013

Kaur, S., Das, K., Amrinder, N., Kanika, S., Meena, P., Gagandeep, I., \& Arash, R. (2009). Stress and coping in the nursing students. J Ment Health Hum Behav, 14(1), 51-56.

Labrague, L. J. (2014). Stress, stressors, and stress responses of student nurses in a government nursing school.

Lo, R. (2002). A longitudinal study of perceived level of stress, coping and self-esteem of undergraduate nursing students: an Australian case study. $J$ Adv Nurs, 39(2), 119-126. https://doi.org/10.1046/j.1365-2648.2000.02251.x

Maville, J. A., Tucker, B. A., \& Kranz, P. L. (2004). Perceived Stress Reported by Nurse Practitioner Students. Journal of the American Academy of Nurse Practitioners, 16(6), 257-262. https://doi.org/10.1111/j.1745-7599.2004.tb00448.x 
Mohamed, B. M., \& Ahmed, E. S. (2012). Perception of Nursing Students towards Clinical Stressors in the Faculty of Applied Medical Sciences-Al Jouf University-Saudia Arabia. Journal of American Science, 8(12).

Nolan, G., \& Ryan, D. (2008). Experience of stress in psychiatric nursing students in Ireland. Nursing Standard, 22(43), 35-43. https://doi.org/10.7748/ns2008.07.22.43.35.c6583

Payne, N. (2001). Occupational stressors and coping as determinants of burnout in female hospice nurses. $J A d v$ Nurs, 33(3), 396-405. https://doi.org/10.1046/j.1365-2648.2001.01677.x

Reeve, K. L., Shumaker, C. J., Yearwood, E. L., Crowell, N. A., \& Riley, J. B. (2013). Perceived stress and social support in undergraduate nursing students' educational experiences. Nurse Education Today, 33(4), 419-424. https://doi.org/10.1016/j.nedt.2012.11.009

Ross, R., Zeller, R., Srisaeng, P., Yimmee, S., Somchid, S., \& Sawatphanit, W. (2005). Depression, Stress, Emotional Support, and Self-Esteem among Baccalaureate Nursing Students in Thailand. International Journal of Nursing Education Scholarship (Vol. 2).

Seyedfatemi, N., Tafreshi, M., \& Hagani, H. (2007). Experienced stressors and coping strategies among Iranian nursing students. BMC Nursing, 6(1), 11. https://doi.org/10.1186/1472-6955-6-11

Shaban, I. A., Khater, W. A., \& Akhu-Zaheya, L. M. (2012). Undergraduate nursing students\&\#x2019; stress sources and coping behaviours during their initial period of clinical training: A Jordanian perspective. Nurse Education in Practice, 12(4), 204-209. https://doi.org/10.1016/j.nepr.2012.01.005

Sheu, S., Lin, H.-S., \& Hwang, S.-L. (2002). Perceived stress and physio-psycho-social status of nursing students during their initial period of clinical practice: the effect of coping behaviors. International Journal of Nursing Studies, 39(2), 165-175. https://doi.org/10.1016/S0020-7489(01)00016-5

Sheu, S., Lin, H., Hwang, S., Yu, P., Hu, W., \& Lou, M. (1997). The development and testing of perceived stress scale of clinical practice. Nursing Research (Republic of China), 5(4), 341-351.

Shriver, C. B., \& Scott-Stiles, A. (2000). Health habits of nursing versus non-nursing students: A longitudinal study. Journal of Nursing Education, 39(7), 308.

Singh, C., Sharma, S., \& Shama, R. (2011). Level of stress and coping strategies used by nursing interns. Nursing and Midwifery Research Journal, 7(4), 152, 160.

Timmins, F., \& Kaliszer, M. (2002). Aspects of nurse education programmes that frequently cause stress to nursing students - fact-finding sample survey. Nurse Education Today, 22(3), 203-211. https://doi.org/10.1054/nedt.2001.0698

Zhao, F.-F., Lei, X.-L., He, W., Gu, Y.-H., \& Li, D.-W. (2015). The study of perceived stress, coping strategy and self-efficacy of Chinese undergraduate nursing students in clinical practice. International Journal of Nursing Practice, 21(4), 401-409. https://doi.org/10.1111/ijn.12273

Zupiria, X., Huitzi Egilegor, X., Jose Alberdi Erice, M., Jose Uranga Iturriotz, M., Eizmendi Garate, I., Barandiaran Lasa, M., \& Sanz Cascante, X. (2007). Stress sources in nursing practice. Evolution during nursing training. Nurse Education Today, 27(7), 777-787. https://doi.org/10.1016/j.nedt.2006.10.017

\section{Copyrights}

Copyright for this article is retained by the author(s), with first publication rights granted to the journal.

This is an open-access article distributed under the terms and conditions of the Creative Commons Attribution license (http://creativecommons.org/licenses/by/4.0/). 